Check for updates

Cite this: RSC Adv., 2018, 8, 17462

\title{
Weak magnetic field enhances the activation of peroxymonosulfate by $\mathrm{ZnO} \mathrm{Fe}_{3} \mathrm{O}_{4} \dagger$
}

\author{
Haodi Zhao, Jing Zhang, (D) * Qian Ye, Hao Xu, Guanyu Zhou, Meijing Wang \\ and Wanning Deng
}

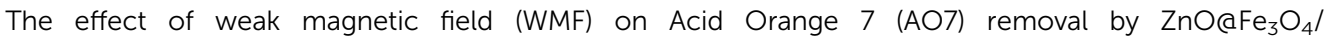
peroxymonosulphate (PMS) was investigated. The results showed that the $\mathrm{AO} 7$ sequestration rate enhanced progressively to $0.14183 \mathrm{~min}^{-1}$ in the presence of WMF, approximately 3 times the $0.04966 \mathrm{~min}^{-1}$ in the absence of $\mathrm{WMF} . \mathrm{SO}_{4}{ }^{-}-\mathrm{SO}_{5}{ }^{\cdot-}$ and $\mathrm{O}_{2}{ }^{\cdot-}$ radicals were generated from the

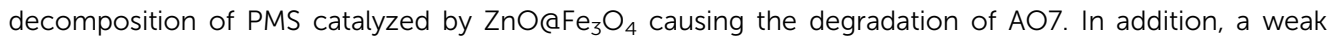
magnetic field promoted the production of $\mathrm{O}_{2}{ }^{-}$- radicals and transition of $\mathrm{Fe}^{3+}$ to $\mathrm{Fe}^{2+}$. Radical-pair theory was used in this study to describe the role of WMF and a possible reaction mechanism was derived. Based on that, the influence of magnetic field flux intensity, $\mathrm{pH}$ and the reusability of $\mathrm{ZnO} \mathrm{FFe}_{3} \mathrm{O}_{4}$ were investigated in this paper.

Received 11th April 2018

Accepted 3rd May 2018

DOI: $10.1039 / \mathrm{c} 8 \mathrm{ra0} 3108 \mathrm{~h}$

rsc.li/rsc-advances

the reason for the acceleration of reactions, which could be explained by the radical-pair theory. ${ }^{9}$ However, researches on the magnetic field to enhance the degradation of pollutants in water have been mostly restricted to ZVI and photocatalytic system. ${ }^{10-13}$ To date, few attempts has been made to investigate the role of WMF in peroxymonosulphate (PMS) system.

Researches have shown that PMS can be effectively activated by many magnetic catalysts. ${ }^{14-16}$ Among them, $\mathrm{ZnO@Fe} \mathrm{O}_{3}$ is a much attractive material for the disinfection of water due to its high chemical stability and it exhibits strong catalytic efficiency and high adsorption capability. In addition, $\mathrm{ZnO} @ \mathrm{Fe}_{3} \mathrm{O}_{4}$ having optimal magnetic properties and essential surface functionality are most promising materials to resolve various environmental problems due to their easy and rapid separation from solution via magnetic field. ${ }^{17,18}$ More importantly, the catalytic activity of $\mathrm{ZnO} @ \mathrm{Fe}_{3} \mathrm{O}_{4}$ could be influenced by the magnetic field because of its magnetic properties. ${ }^{19}$ Based on that, $\mathrm{ZnO} @ \mathrm{Fe}_{3} \mathrm{O}_{4}$ may show a higher activation of PMS in the presence of WMF.

To sum up, the specific objective of this study was focused on the influence of weak magnetic field on the oxidation and degradation of Acid Orange $7(\mathrm{AO} 7)$ by $\mathrm{ZnO} @ \mathrm{Fe}_{3} \mathrm{O}_{4} / \mathrm{PMS}$ system. This paper attempted to establish the mechanism model of the reaction and to explain the role of WMF in this system. So the main issues addressed in this paper are: (a) the effect of WMF in $\mathrm{ZnO} @ \mathrm{Fe}_{3} \mathrm{O}_{4} / \mathrm{PMS}$ system, (b) the possible reaction mechanism and the role of WMF and, (c) some other influence factors.

\section{Experimental section}

College of Architecture \& Environment, Sichuan University, Sichuan 610065, China. E-mail: zjing428@163.com

$\dagger$ Electronic supplementary information (ESI) available. See DOI:

\subsection{Materials}

Zinc acetate dihydrate $(\geq 98 \%$ ), ferrous chloride tetrahydrate $(\geq 99 \%$ ), ferric chloride hexahydrate (ACS reagent, 97\%) and 
ammonia solution $\left(25 \% \mathrm{NH}_{3}\right.$ in $\left.\mathrm{H}_{2} \mathrm{O}\right)$ were procured from Chengdu Kelong Chemical Reagent Co., Ltd. (China). AO7, PMS, furfuryl alcohol, $t$-butyl alcohol, methanol and benzoquinone were procured from Sigma-Aldrich Co. LLC. (USA). Deionized water was used in all experiments.

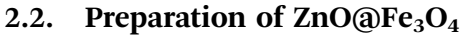

A stock solution of $\mathrm{Zn}(\mathrm{Ac})_{2}$ was prepared by dissolving $\mathrm{Zn}(\mathrm{Ac})_{2} \cdot 2 \mathrm{H}_{2} \mathrm{O}$ into deionized water. Ammonia was slowly added to the $\mathrm{Zn}(\mathrm{Ac})_{2}$ solution until it is clear. Then a stock solution of $\mathrm{FeCl}_{2}$ and $\mathrm{FeCl}_{3}$ was prepared in deionized water. The two solutions were added to the above $\mathrm{Zn}(\mathrm{Ac})_{2}$ solution with rapid stirring. After that, the mixture was stirred for a while and then transferred to a hydrothermal reactor. After reaction, on cooling to room temperature, the precipitate was separated centrifugally, washed with twice-distilled water and absolute ethanol, and then dried. Finally, it was calcined in a muffle furnace and then $\mathrm{ZnO} @ \mathrm{Fe}_{3} \mathrm{O}_{4}$ was synthesized.

\subsection{Batch experiments and catalyst characterization}

Batch experiments were carried out to investigate the feasibility of $\mathrm{AO} 7$ removal by $\mathrm{ZnO} @ \mathrm{Fe}_{3} \mathrm{O}_{4}$ in the presence of WMF. Several pieces of neodymium-iron-boron permanent magnets (the maximum magnetic field intensity of each one was $10 \mathrm{mT}$ ) were employed to offer magnetic field. The axis line of the reactor (a $250 \mathrm{~mL}$ beaker) and the center of the magnetic field coincided. This magnetic field was weak and would be referred as weak magnetic field (WMF) hereafter. Unless otherwise specified, two magnets were used at the same time in the experiments.

The influence of magnetic field intensity was investigated by fixing $\mathrm{pH}$ at 6.0 while varying the magnetic field intensity from about $10 \mathrm{mT}$ to $40 \mathrm{mT}$ (by changing the number of magnets from one to four). Batch reduction tests were conducted by

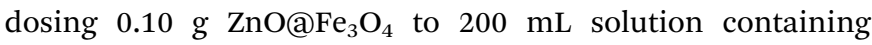
$7 \mathrm{mg} \mathrm{L}^{-1} \mathrm{AO} 7$ to investigate the effect of $\mathrm{pH}$. The $\mathrm{pH}$ was varied from 2.0 to 10.0 for different tests. $0.1 \mathrm{mmol} \mathrm{L}^{-1}$ of inhibitors was used in the radicals inhibition experiment and corresponding radicals can be sufficiently inhibited..$^{20-22}$ If it was not otherwise specified, the experiments were carried out open to the air. Since $\mathrm{ZnO} @ \mathrm{Fe}_{3} \mathrm{O}_{4}$ is ferromagnetic, the presence of WMF can induce the aggregation of $\mathrm{ZnO} @ \mathrm{Fe}_{3} \mathrm{O}_{4}$, which may subsequently affect $\mathrm{AO} 7$ removal by $\mathrm{ZnO} @ \mathrm{Fe}_{3} \mathrm{O}_{4}$. So the solution was mixed at $300 \mathrm{rpm}$ using a mechanical stirrer (D2004W, Shanghai Sile Instrument Co., Ltd). The AO7 concentration remained in solution was determined by measuring the absorbance of the solution at $484 \mathrm{~nm}$ on a Cary 50 UV-vis spectrophotometer (Varian, USA). The concentrations of iron and zinc leached into reaction solutions were monitored by spectrophotometry and atomic absorption spectroscopy (AAS, Analyst 300, P. E. Inc.). All batch experiments lasted for $30 \mathrm{~min}$. The experimental device was constructed as shown in Scheme S1. $\dagger$

After batch tests, $\mathrm{ZnO} @ \mathrm{Fe}_{3} \mathrm{O}_{4}$ were collected by magnetic separation, washed with deionized water and vacuum dried at $50{ }^{\circ} \mathrm{C}$ for $1 \mathrm{~h}$. Such a pre-treatment could not change the particle size and crystalline structure of $\mathrm{ZnO} @ \mathrm{Fe}_{3} \mathrm{O}_{4}$ samples. The crystalline structure of various samples was analysed using powder X-ray diffraction (XRD). The spectra were obtained on a Bruker D8-Advance X-ray diffractometer with $\mathrm{Cu} \mathrm{K} \alpha$ radiation $(\lambda=1.5418 \mathrm{~A})$, with accelerating voltage and current of $40 \mathrm{kV}$ and $40 \mathrm{~mA}$, respectively. Scanning electron microscopy (SEM), performed on a FEI Inspect F50, was used to evaluate the morphology, size and textural information of the samples. The surface chemical compositions of $\mathrm{ZnO} @ \mathrm{Fe}_{3} \mathrm{O}_{4}$ were identified by X-ray photoelectron spectroscopy (XPS, ESCALAB250Xi, ThermoFisher Scientific) using the $\mathrm{Mg} \mathrm{K} \alpha$ line $(h t=1253.6 \mathrm{eV})$ as an excitation source. The pressure in the XPS analysis chamber was maintained at 109 mbar. The binding energies of all peaks were referenced to the $\mathrm{C}(1 \mathrm{~s})$ line $(285.0 \mathrm{eV})$. After Shirley background subtraction, the spectra were analyzed by the XPSPeak 4.1 Program. The magnetic hysteresis loop measurement for the pristine $\mathrm{ZnO@} \mathrm{Fe}_{3} \mathrm{O}_{4}$ was carried out using a vibrating sample magnetometer (VSM; Lake Shore 735, Lake Shore Cryotronics, Westerville, $\mathrm{OH})$.

\section{Results and discussion}

\subsection{Influence of WMF on $\mathrm{AO} 7$ removal by $\mathrm{ZnO@Fe} \mathrm{F}_{3} \mathrm{O}_{4} / \mathrm{PMS}$ system}

The WMF effect on $\mathrm{AO} 7$ removal by $\mathrm{ZnO} @ \mathrm{Fe}_{3} \mathrm{O}_{4}$ was investigated at $\mathrm{pH}$ 6.0, as shown in Fig. 1. In control experiments, almost no disappearance of AO7 was observed when only PMS was added into the solution of $\mathrm{AO} 7$ both in the presence and absence of WMF (Fig. S1 $\dagger$ ). However, as shown in Fig. 1, the $\mathrm{ZnO} @ \mathrm{Fe}_{3} \mathrm{O}_{4}$ without PMS removed $10 \%$ of AO7 within 30 min, which stemed from the adsorption of the catalyst. Furthermore, the degradation rate was not promoted by WMF, which could indicate that the magnetic field did not affect the adsorption of the catalyst.

After adding PMS, the $\mathrm{ZnO} @ \mathrm{Fe}_{3} \mathrm{O}_{4}$ removed $80 \%$ of $\mathrm{AO} 7$ within $30 \mathrm{~min}$. The results indicated that $\mathrm{ZnO} @ \mathrm{Fe}_{3} \mathrm{O}_{4}$ may activate the PMS to remove organic pollutants. Turning now to the experimental in the presence of $\mathrm{WMF}$, the $\mathrm{ZnO} @ \mathrm{Fe}_{3} \mathrm{O}_{4}$ exhibited much higher catalytic activity and removed $95 \%$ of AO7 within 30 min. Moreover, it removed more than $80 \%$ within only $12 \mathrm{~min}$, which is a $30 \%$ improvement over the absence of WMF. Thus, the necessary reaction time to achieve complete AO7 removal could be greatly shortened by introducing WMF.

The kinetics of AO7 elimination with or without WMF could be well simulated with pseudo-first-order rate law (eqn (1))

$$
\frac{\mathrm{d}[\mathrm{AO} 7]}{\mathrm{d} t}=-k_{\mathrm{obs}}[\mathrm{AO} 7]
$$

where $k_{\text {obs }}$ is the pseudo-first-order rate constant $\left(\mathrm{min}^{-1}\right)$ of $\mathrm{AO} 7$ removal by $\mathrm{ZnO} @ \mathrm{Fe}_{3} \mathrm{O}_{4} / \mathrm{PMS}$ system. The $\mathrm{AO} 7$ sequestration rate was enhanced progressively to $0.14183 \mathrm{~min}^{-1}$ with WMF, approximately 3 times of $0.04966 \mathrm{~min}^{-1}$ in the absence of WMF. It indicated the degradation rate of $\mathrm{AO} 7$ was significantly increased with WMF. Hence, WMF have played a vital role in activating PMS and removing AO7.

\subsection{Influence of radical inhibitors on $\mathrm{AO7}$ removal by $\mathrm{ZnO@Fe} \mathrm{O}_{4} / \mathrm{PMS}$ system}

To speculate the role of WMF in this system, it is necessary to identify the nature of radicals generated from the 


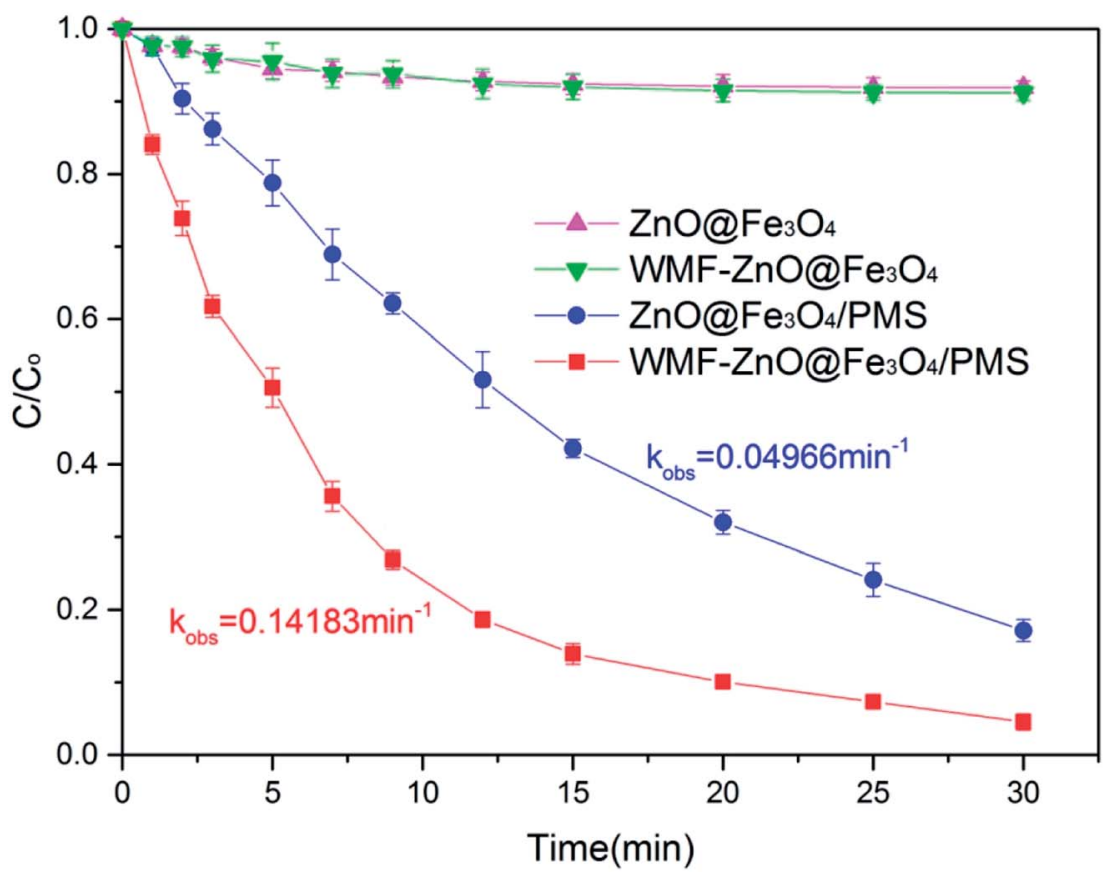

Fig. 1 WMF accelerated $\mathrm{AO} 7$ removal by $\mathrm{ZnO}\left(\mathrm{aFe} \mathrm{O}_{3} / \mathrm{PMS}\right.$ system. Reaction conditions: $[\mathrm{PMS}]_{0}=5 \times 10^{-4} \mathrm{M}$ or $0 \mathrm{M}$, $[\mathrm{AO} 7]_{0}=0.02 \mathrm{mM}$, $\left[\mathrm{ZnO} @ \mathrm{Fe}_{3} \mathrm{O}_{4}\right]_{0}=0.5 \mathrm{~g} \mathrm{~L}^{-1}, \mathrm{pH}=6.0 . \mathrm{C}$ and $\mathrm{C}_{0}$ are $\mathrm{AO} 7$ concentration at time $t$ and initial.

decomposition of PMS catalyzed by $\mathrm{ZnO} @ \mathrm{Fe}_{3} \mathrm{O}_{4}$ and compare the radical production under the condition of WMF. According to relevant research, ${ }^{23} \mathrm{OH}^{\circ}, \mathrm{SO}_{4}{ }^{-{ }^{-}} / \mathrm{SO}_{5}{ }^{-{ }^{-}}$and $\mathrm{O}_{2}{ }^{-{ }^{-}}$radicals may exist in the system. Hence, both in the presence and absence of WMF, different radical inhibitors were added to the system of $\mathrm{ZnO} @ \mathrm{Fe}_{3} \mathrm{O}_{4} / \mathrm{PMS}$.

When excess furfuryl alcohol was added to act as inhibitors of various radicals, the $\mathrm{AO} 7$ degradation was greatly suppressed and only about $10 \%$ of $\mathrm{AO} 7$ was removed within 30 min both in the presence and absence of WMF (Fig. 2a). It was roughly consistent with $\mathrm{AO} 7$ degradation by the adsorption of the catalyst which further illustrated that the degradation of $\mathrm{AO} 7$ mainly came from the oxidation of radicals. Besides, the $\mathrm{AO} 7$ degradation rate was almost the same with WMF. This was consistent with the above

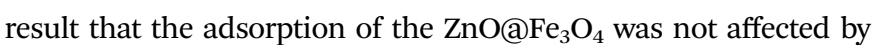
the magnetic field.

As shown in Fig. 2b, the addition of excess $t$-butyl alcohol as a well-known $\mathrm{OH}^{\cdot}$ radical scavenger, has little affect on the $\mathrm{AO} 7$ degradation. Both in the presence and absence of WMF, the degradation rates of $\mathrm{AO} 7$ were almost the same whether or not $t$ butyl alcohol added (compared with Fig. 1). Therefore, there was almost no $\mathrm{OH}^{\cdot}$ radical in this system. Even with WMF, the generation of $\mathrm{OH}^{*}$ radical has not been promoted. In the control experiments, $\mathrm{AO} 7$ was hardly degraded by $\mathrm{ZnO} @ \mathrm{Fe}_{3} \mathrm{O}_{4} / \mathrm{H}_{2} \mathrm{O}_{2}$ system (Fig. S2 $\uparrow$ ), which suggested that $\mathrm{ZnO} @ \mathrm{Fe}_{3} \mathrm{O}_{4}$ did not have the ability to activate peroxy species to produce $\mathrm{OH}^{\cdot}$ radicals.

In the absence of WMF, when excess of methanol was added to act as the $\mathrm{SO}_{4}{ }^{-} / \mathrm{SO}_{5}{ }^{--}$radicals scavenger, the $\mathrm{AO} 7$ degradation was suppressed by about $30 \%$ (Fig. 2c). Surprisingly, in the presence of WMF, the degradation rate of $\mathrm{AO} 7$ was different. As shown in Fig. 2c, the $\mathrm{AO} 7$ degradation was also suppressed by methanol in the presence of WMF, which showed the presence of $\mathrm{SO}_{4}{ }^{-{ }^{-}} / \mathrm{SO}_{5}{ }^{-{ }^{-}}$radicals in the system. However, comparing with no WMF system, the removal rate of $\mathrm{AO} 7$ was increased. It is speculate that other radicals may play an important role and be affected by WMF. According to related research, ${ }^{23} \mathrm{O}_{2}{ }^{\cdot-}$ radicals may exist in this system. And when excess of benzoquinone was added to act as the $\mathrm{O}_{2}{ }^{-}$radicals scavenger, the $\mathrm{AO} 7$ degradation was suppressed by about $60 \%$ and the degradation rate was almost the same in the presence of WMF (Fig. 2d). These evidences demonstrates that both $\mathrm{SO}_{4}{ }^{-{ }^{-}} / \mathrm{SO}_{5}{ }^{{ }^{-}-}$and $\mathrm{O}_{2}{ }^{{ }^{-}-}$radi-

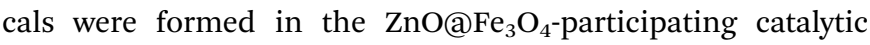
reaction, but $\mathrm{O}_{2}{ }^{--}$radicals exhibited a stronger effect than $\mathrm{SO}_{4}{ }^{--} / \mathrm{SO}_{5}{ }^{-{ }^{-}}$radicals in the $\mathrm{AO} 7$ degradation by PMS catalyzed by $\mathrm{ZnO@Fe} \mathrm{O}_{4}$. In addition, the results illustrated that the WMF did not affect the $\mathrm{SO}_{4}{ }^{-} / \mathrm{SO}_{5}{ }^{-{ }^{-}}$radicals but the $\mathrm{O}_{2}{ }^{\cdot-}$ radicals in $\mathrm{ZnO} @ \mathrm{Fe}_{3} \mathrm{O}_{4} / \mathrm{PMS}$ system. The production rate of $\mathrm{O}_{2}{ }^{\cdot-}$ radicals increased in the presence of WMF thereby enhancing the $\mathrm{AO} 7$ degradation in $\mathrm{ZnO} @ \mathrm{Fe}_{3} \mathrm{O}_{4} / \mathrm{PMS}$ system. Since $\mathrm{O}_{2}{ }^{-}$radicals were important in this system, it was necessary to check the origin of $\mathrm{O}_{2}{ }^{-{ }^{-}}$radicals. Hence, continuous $\mathrm{N}_{2}$ purging was carry out to explore the role of $\mathrm{O}_{2}$ on the generation of $\mathrm{O}_{2}{ }^{--}$radicals. As shown in Fig. $\mathrm{S} 3, \dagger$ in the absence of dissolved oxygen, the $\mathrm{AO} 7$ degradation reduced only $6 \%$ in the absence of WMF and 7\% in the presence of WMF, compared to experiments in open air (Fig. 1). It suggested that although $\mathrm{O}_{2}$ did play a role in the system, it was not a significant factor. Hence, it can be speculated that most of $\mathrm{O}_{2}{ }^{--}$radicals was generated by the reaction of $\mathrm{ZnO} @ \mathrm{Fe}_{3} \mathrm{O}_{4}$ with PMS.

\subsection{Reaction mechanism of $\mathrm{ZnO} @ \mathrm{Fe}_{3} \mathrm{O}_{4} / \mathrm{PMS}$ system and the roles of WMF}

In order to further reveal the reaction mechanism, it is necessary to figure out how the radicals produced and how the WMF 

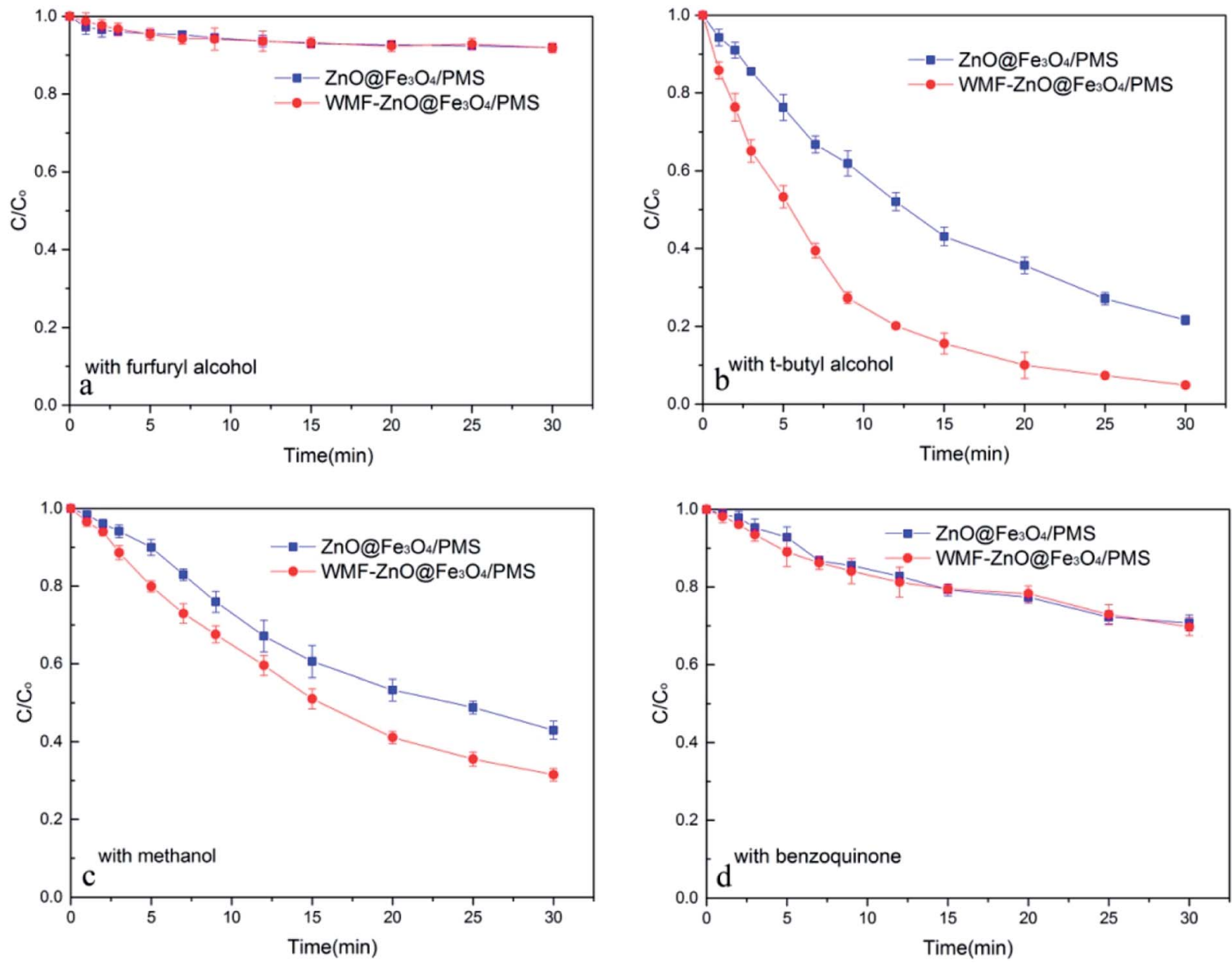

Fig. 2 The influence of radical inhibitors on the $\mathrm{AO} 7 \mathrm{removal}$ by $\mathrm{ZnO@Fe} \mathrm{O}_{4} / \mathrm{PMS}$ system. Reaction conditions: $[\mathrm{PMS}]_{0}=5 \times 10^{-4} \mathrm{M},[\mathrm{AO}]_{0}=$ $0.02 \mathrm{mM},\left[\mathrm{ZnO} \mathrm{aFe}_{3} \mathrm{O}_{4}\right]_{0}=0.5 \mathrm{~g} \mathrm{~L}^{-1}, \mathrm{pH}=6.0$.

acted on the radicals. And the generation of radicals is closely related to the surface properties of the catalyst in heterogeneous catalytic reactions. ${ }^{24}$ Therefore, XRD and SEM were used to analyze the characteristics of catalyst. X-ray powder diffraction was used to identify the components of three samples as shown in Fig. 3. The observed diffraction peaks at $2 \theta=30.0^{\circ}, 35.4^{\circ}$, $43.0^{\circ}, 53.4^{\circ}, 56.9^{\circ}$ and $62.5^{\circ}$ correspond to the (220), (311), (400), (422), (511) and (440) planes of $\mathrm{Fe}_{3} \mathrm{O}_{4}$ (JCPDS no. 19$0629) .{ }^{25-29}$ And it showed diffraction peaks at $2 \theta=31.7^{\circ}, 34.4^{\circ}$, $36.2^{\circ}, 47.5^{\circ}, 56.5^{\circ}$ and $62.8^{\circ}$, which correspond to the (100), (002), (101), (102), (110) and (103) Miller indices assigned to ZnO hexagonal wurtzite lattice (JCPDS, 36-1451). ${ }^{30}$ By comparing and analyzing the XRD patterns of the three samples, the proportion of the components of the three samples was obtained, shown as Table 1 . The content of $\mathrm{ZnO}$ decreased in the sample after use, since $\mathrm{ZnO}$ reacted with the PMS causing $\mathrm{Zn}^{2+}$ to dissolve. ${ }^{31}$ And Table 1 also indicated that the reaction was hardly affected by WMF (comparing with the sample 1 and sample 2). Fig. 3 also gives the SEM image of the

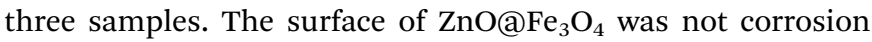
after catalytic experimentation and even with WMF. We then demonstrated that the catalytic reduction of PMS was induced predominately by the heterogeneous catalysis on the surface of
$\mathrm{ZnO} @ \mathrm{Fe}_{3} \mathrm{O}_{4}$, because the iron concentration leaching into the solutions was very low (less than $0.015 \mathrm{mg} \mathrm{L}^{-1}$ ) both in the presence and absence of WMF, which could not yield a marked activation of PMS. ${ }^{23}$ And the zinc concentration leaching into the solutions was about $5.8 \mathrm{mg} \mathrm{L}^{-1}$, which came from the

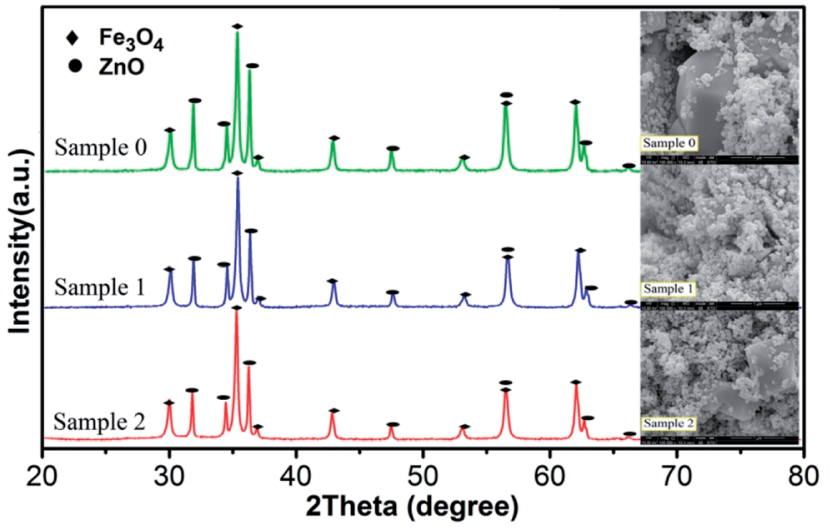

Fig. 3 XRD patterns and SEM images of $\mathrm{ZnO} \mathrm{aFe}_{3} \mathrm{O}_{4}$ : Sample 0, before used; Sample 1, after catalytic experimentation without WMF; Sample 2, after catalytic experimentation with WMF. 
Table 1 The components of the three samples analyzed by XRD patterns

\begin{tabular}{lll}
\hline & $\mathrm{Fe}_{3} \mathrm{O}_{4}$ & $\mathrm{ZnO}$ \\
\hline Sample 0 & $57.76 \%$ & $42.24 \%$ \\
Sample 1 & $63.30 \%$ & $36.70 \%$ \\
Sample 2 & $63.63 \%$ & $36.37 \%$
\end{tabular}

reaction between $\mathrm{ZnO}$ and $\mathrm{PMS} .^{31}$ This reaction might be a small amount which would hardly cause corrosion of the catalyst. And in the control experiments, $5.8 \mathrm{mg} \mathrm{l}^{-1} \mathrm{Zn}^{2+}$ could not activate the PMS (Fig. S4 $\dagger$ ). In addition, the concentrations of iron and zinc leaching into reaction solutions did not change in the presence of WMF. The same conclusion was drawn with the catalyst characterization. This is different from the report of Ren et al., which concluded that the corrosion of the ZVI increased with WMF.11 However, this study found that the catalytic activity of $\mathrm{ZnO} @ \mathrm{Fe}_{3} \mathrm{O}_{4}$ was improved by the magnetic field but the corrosion of it did not increase, which could reduce the secondary pollution caused by the dissolution of the catalyst.

In order to analyze the effect of WMF on the catalyst, XPS was used for the analysis of the proportion of $\mathrm{Fe}^{3+}$ and $\mathrm{Fe}^{2+}$ in the catalyst. As shown in Fig. 4 and Table 2, the proportion of $\mathrm{Fe}^{3+}$ in the catalyst was increased and $\mathrm{Fe}^{2+}$ was reduced after the experiment without WMF. Nevertheless, in the presence of WMF, the proportion of $\mathrm{Fe}^{2+}$ and $\mathrm{Fe}^{3+}$ in the catalyst was almost the same as the freshly-made catalyst, which showed that WMF promoted the transition and cycle of $\mathrm{Fe}^{3+}$ and $\mathrm{Fe}^{2+}$ on catalyst surface. Further analysis showed that surface reactions between PMS and $\mathrm{Fe}^{3+}$ may make a large contribution to the PMSactivating ability of $\mathrm{ZnO} @ \mathrm{Fe}_{3} \mathrm{O}_{4}$ in the presence of WMF. Combined with the analysis of the radicals, presumably, $\mathrm{O}_{2}{ }^{\cdot-}$ radicals might originate from the reaction of $\mathrm{Fe}^{3+}$ and PMS, which was promoted in the presence of WMF.

Based on the above discussions and other related researches, the likely catalytic mechanism for the activation of PMS by $\mathrm{ZnO@Fe} \mathrm{O}_{4}$ and the role of WMF is proposed in Scheme 1. PMS molecules might be adsorbed on the surface of $\mathrm{ZnO} @ \mathrm{Fe}_{3} \mathrm{O}_{4}$ and then activated by the bound $\mathrm{Fe}^{2+}$ and $\mathrm{Fe}^{3+}$ to generate $\mathrm{SO}_{4}{ }^{--}$/ $\mathrm{SO}_{5}{ }^{-}$and $\mathrm{O}_{2}{ }^{--}$radicals. At the same time, WMF contributed to the transition of $\mathrm{Fe}^{2+}$ and $\mathrm{Fe}^{3+} \cdot{ }^{23,32}$ In addition, $\mathrm{ZnO}$ partially reacted with PMS to produce $\mathrm{SO}_{4}{ }^{{ }^{-}} / \mathrm{SO}_{5}{ }^{--}$radicals, ${ }^{31}$ which could cause $\mathrm{ZnO}$ to dissolve, but as mentioned previously, it could not be affected by the magnetic field. Besides, most of the $\mathrm{ZnO}$ remains in the catalyst. Because of the high oxidizing ability of radicals, the generated $\mathrm{SO}_{4}{ }^{-}-\mathrm{SO}_{5}{ }^{--}$and $\mathrm{O}_{2}{ }^{--}$radicals initiate the subsequent degradation of AO7. The role of WMF could be explained by the radical-pair theory of magneto chemistry. ${ }^{9,33,34}$ The radical pair may be classified as a singlet or as a triplet radical pair according to a vector model. In a reaction system, triplet-singlet $(\mathrm{T}-\mathrm{S})$ intersystem crossing involves conversion of $\mathrm{T}_{+}, \mathrm{T}_{-}$, or $\mathrm{T}_{\mathrm{o}}$ to $\mathrm{S}$. Moreover, the rate of $\mathrm{T}-\mathrm{S}$ intersystem crossing in an indirect fashion depends on the magnetic field strength, since an external field caused $\mathrm{T}_{+}$and $\mathrm{T}_{-}$
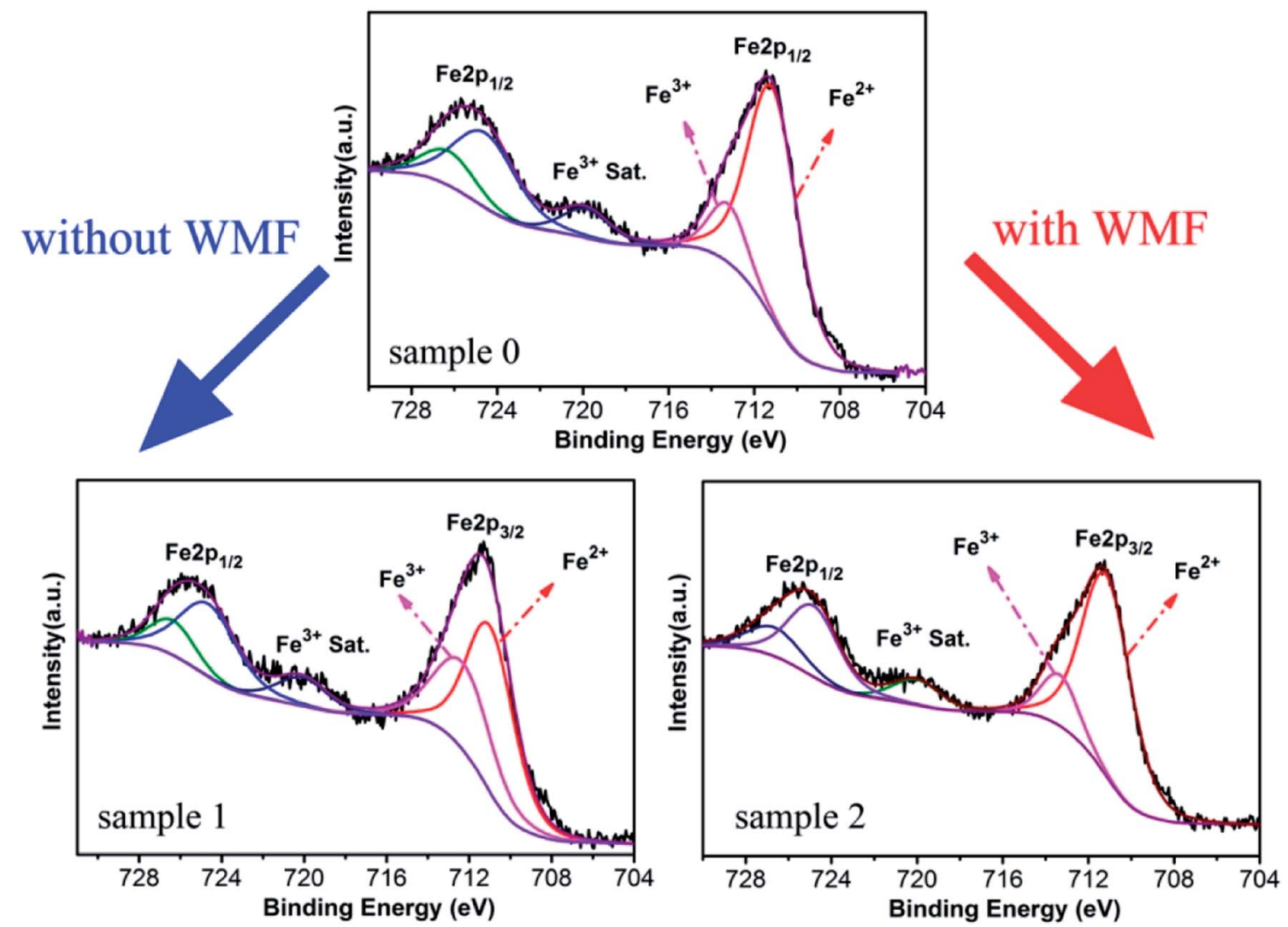

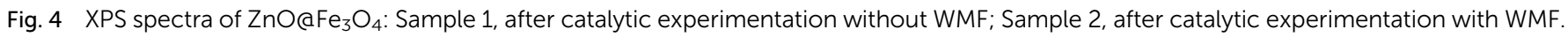


Table 2 The proportion of $\mathrm{Fe}^{3+}$ and $\mathrm{Fe}^{2+}$ in the catalyst analyzed by XPS spectra: Sample 1, after catalytic experimentation without WMF; Sample 2, after catalytic experimentation with WMF

\begin{tabular}{lll}
\hline & $\mathrm{Fe}^{3+}$ & $\mathrm{Fe}^{2+}$ \\
\hline Sample 0 & $16.24 \%$ & $83.76 \%$ \\
Sample 1 & $38.46 \%$ & $61.54 \%$ \\
Sample 2 & $18.05 \%$ & $81.95 \%$
\end{tabular}

to split in energy from $\mathrm{S}$. As a result, conversion of $\mathrm{T}_{+}$and $\mathrm{T}_{-}$to $\mathrm{S}$ was slowed down with magnetic field, which increased the reaction between radicals and $\mathrm{AO}$. Hence, the production rate of radicals was increased since the consumption of radicals has been promoted. And it was the way that WMF promoted the reaction. Moreover, at the same time, the faster consumption of radicals also promoted the reaction of $\mathrm{Fe}^{3+}$ and PMS. Consequently, the transition of $\mathrm{Fe}^{3+}$ to $\mathrm{Fe}^{2+}$ was promoted by WMF which may improve the recycling capacity of the catalyst.

\subsection{Influence of magnetic field intensity on $\mathrm{AO} 7$ removal by $\mathrm{ZnO@Fe}_{3} \mathrm{O}_{4} / \mathrm{PMS}$ system}

The intensity of magnetic field is an important factor in the applied magnetic field, which would ultimately affect the removal effect of $\mathrm{AO} 7$. Therefore, the feasibility of $\mathrm{AO} 7$ removal by $\mathrm{ZnO} @ \mathrm{Fe}_{3} \mathrm{O}_{4}$ under different magnetic field intensity was investigated and shown in Fig. 5a. According to the magnetic field intensity from about $10 \mathrm{mT}$ to $40 \mathrm{mT}$, the experimental conditions were divided into WMF1 to WMF4. With WMF of different intensities, the degradation rate of $\mathrm{AO} 7$ was all increased. The $\mathrm{ZnO} @ \mathrm{Fe}_{3} \mathrm{O}_{4}$ with PMS exhibited a higher catalytic activity when the magnetic field intensity was about $20 \mathrm{mT}$ and removed about $95 \%$ of the added $\mathrm{AO} 7$ within $30 \mathrm{~min}$. As the intensity of the applied magnetic field increased gradually, the auxiliary function of the WMF was also observed, but the enhancement effect gradually decreased. And it removed about
$85 \%$ of the added $\mathrm{AO} 7$ within 30 min with the magnetic field of $40 \mathrm{mT}$, only about 5 percent higher than in the absence of WMF. The effect of WMF was similar when the magnetic field intensity was about $10 \mathrm{mT}$ and $30 \mathrm{mT}$. As shown as Fig. 5b, The AO7 sequestration rate constant enhanced from 0.04966 to $0.14183 \mathrm{~min}^{-1}$ with increasing the magnetic field flux intensity from 0 to $20 \mathrm{mT}$. Although the rates of $\mathrm{AO} 7$ removal by $\mathrm{ZnO}_{0} \mathrm{Fe}_{3} \mathrm{O}_{4} / \mathrm{PMS}$ progressively decreased to 0.08797 and $0.07059 \mathrm{~min}^{-1}$, respectively, by increasing the flux intensity of magnetic field to 30 and $40 \mathrm{mT}$, they were larger than that by $\mathrm{ZnO} @ \mathrm{Fe}_{3} \mathrm{O}_{4} / \mathrm{PMS}$ without WMF. To provide a generalized basis for the comparison among different magnetic field intensity, the ratio $\left(R_{\mathrm{WMF}}\right)$ of kinetic constants measured with and without the WMF was calculated, according to eqn (2).

$$
R_{\mathrm{WMF}}=\frac{k_{\text {with WMF }}}{k_{\text {without WMF }}}
$$

Explained by the radical-pair theory, the rate of T-S intersystem crossing related to the magnetic field strength. ${ }^{32}$ When the conversion is sufficiently inhibited, the role of magnetic field reaches saturation. Then the production rate of radicals would not increase with strong magnetic field. In addition, since $\mathrm{ZnO} @ \mathrm{Fe}_{3} \mathrm{O}_{4}$ is ferromagnetic, it might agglomerate in water. Hence the number of catalyst surface active point might reduce with a strong magnetic field, reducing the removal rate of $\mathrm{AO} 7$.

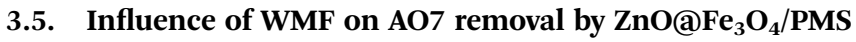 system at different $\mathrm{pHs}$}

In addition to the intensity of the applied magnetic field, the $\mathrm{pH}$ levels were also an external influence factor. The WMF effect on $\mathrm{AO} 7$ removal by $\mathrm{ZnO} @ \mathrm{Fe}_{3} \mathrm{O}_{4}$ at different $\mathrm{pH}$ was investigated over the $\mathrm{pH}$ range of 2.0-10.0 to know the WMF effects at different pH levels. Fig. 6 shows the WMF effects on AO7

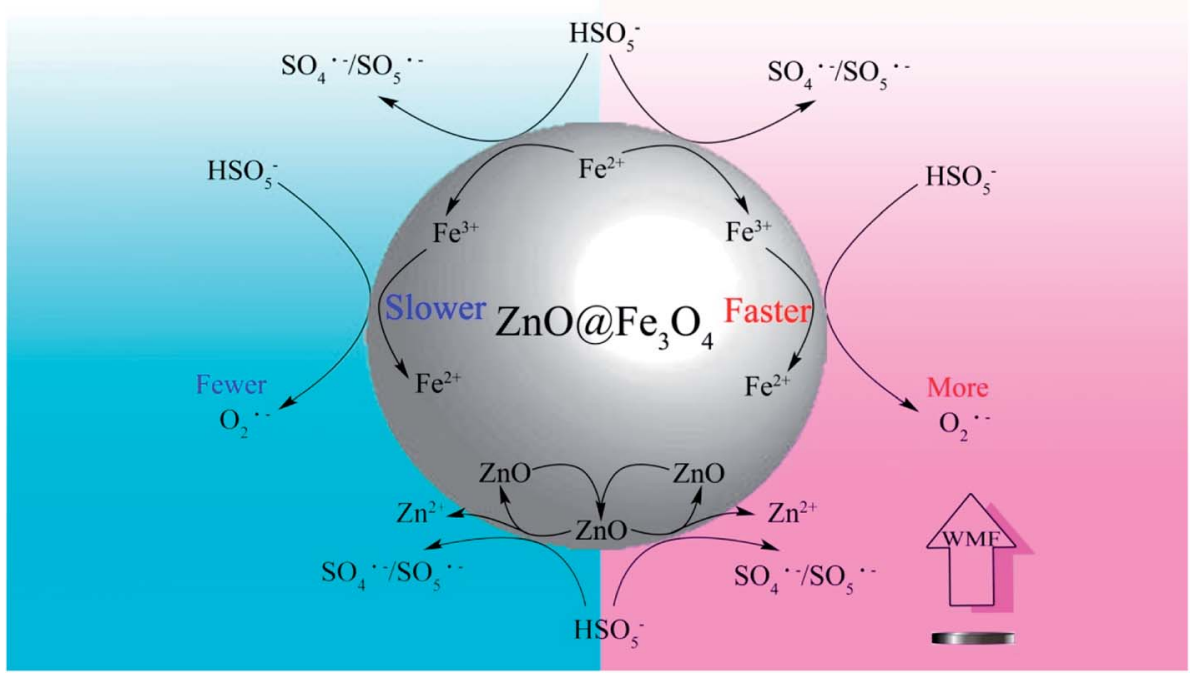

Scheme 1 A mechanism for WMF enhancing the activation of PMS on $\mathrm{ZnO} a F e_{3} \mathrm{O}_{4}$ in the degradation of organic pollutants. 

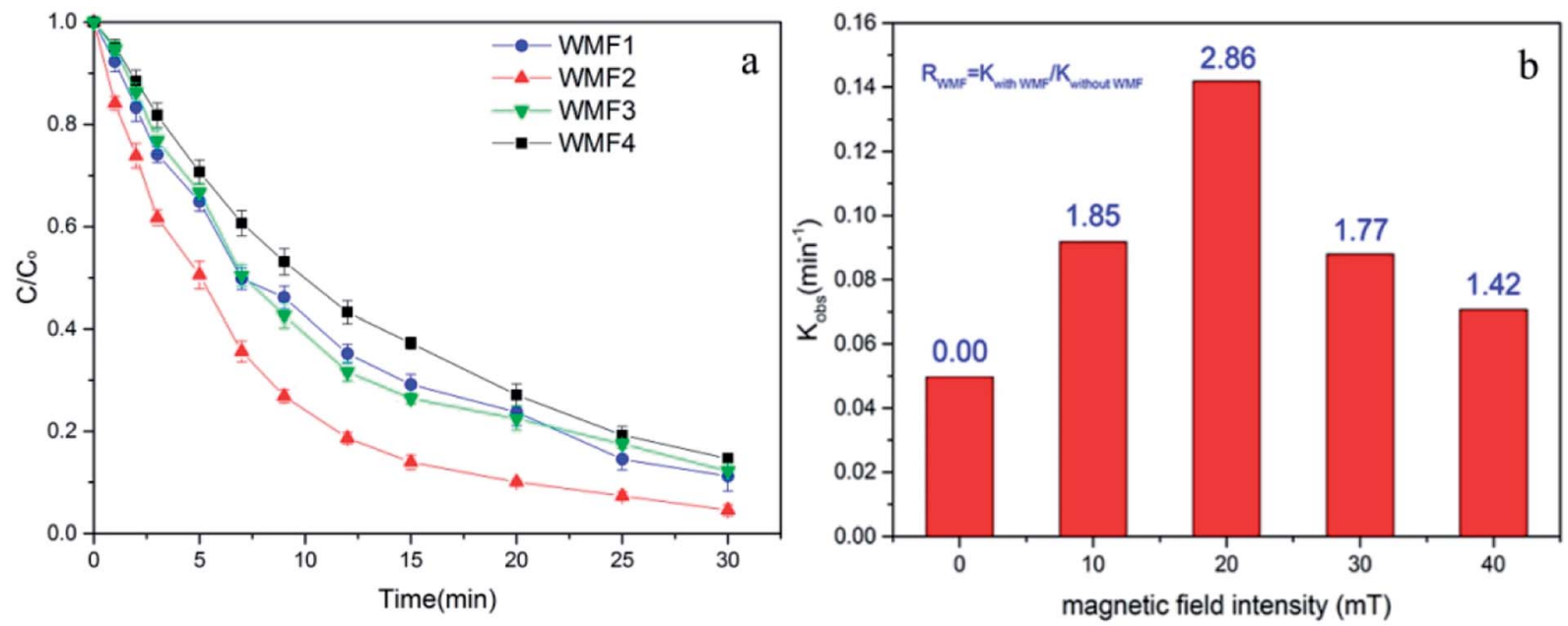

Fig. 5 (a) Influence of WMF on $\mathrm{AO} 7$ removal by $\mathrm{ZnO}\left(\mathrm{Fe}_{3} \mathrm{O}_{4} / \mathrm{PMS}\right.$ system at different magnetic field intensity vary from $10 \mathrm{mT}$ to $40 \mathrm{mT}$. (b) The pseudo-first-order rate constants of $\mathrm{AO} 7$ removal by $\mathrm{ZnO}_{\mathrm{aFe}} \mathrm{O}_{4} / \mathrm{PMS}$ system and $R_{\mathrm{WMF}}$ as a function of the MF flux intensity. Reaction conditions: $[\mathrm{PMS}]_{0}=5 \times 10^{-4} \mathrm{M},[\mathrm{AO}]_{0}=0.02 \mathrm{mM},\left[\mathrm{ZnO} \mathrm{ZFe}_{3} \mathrm{O}_{4}\right]_{0}=0.5 \mathrm{~g} \mathrm{~L}^{-1}, \mathrm{pH}=6.0$.

removal by $\mathrm{ZnO} @ \mathrm{Fe}_{3} \mathrm{O}_{4}$ at various pH levels. In the absence of $\mathrm{WMF}$, the $\mathrm{AO} 7$ removal rate increased with increasing $\mathrm{pH}$ from 2.0 to 8.0 but declined with a further elevation in $\mathrm{pH}$. And the removal rates were very similar at $\mathrm{pH} 6.0$ and 8.0. After the application of WMF, the $\mathrm{AO} 7$ removal rates were increased considerably over the $\mathrm{pH}$ range of 2.0-6.0 and declined with a further elevation in $\mathrm{pH}$. The results showed that the effect of WMF related to the $\mathrm{pH}$ levels of the solution. This might be due to the fact that $\mathrm{pH}$ affected the properties and yield of radicals. In the solution with a high $\mathrm{pH}, \mathrm{SO}_{4}{ }^{--}$radicals reacted with $\mathrm{OH}^{-}$ to form $\mathrm{OH}^{\cdot}$ radicals. ${ }^{35}$ However $\mathrm{OH}^{*}$ radicals would consume $\mathrm{O}_{2}{ }^{\cdot-}$ radicals ${ }^{36}$ which could slow the catalytic reaction. It is worth noting that this process was limited by yield of $\mathrm{SO}_{4}{ }^{-}$ radicals so the reaction rate would not be greatly reduced. Since the consumption of $\mathrm{O}_{2}{ }^{--}$radicals, the promotion of WMF was reduced. In addition, there was an unexpected outcome at $\mathrm{pH}$
2.0. This might be related to the zeta potential and electrostatic adsorption of the catalyst surface. Therefore, thezZeta potential of the catalyst was analyzed. The zeta potential of $\mathrm{ZnO} @ \mathrm{Fe}_{3} \mathrm{O}_{4}$ at $\mathrm{pH} 2$ is +10.13 , much greater than +2.88 at $\mathrm{pH} 4$. Since $\mathrm{AO} 7$ is a negative dye, the positive charge on the surface of the catalyst will interact with AO7. It can be inferred that electrostatic adsorption of the catalyst at $\mathrm{pH} 2$ leaded to rapid removal of $\mathrm{AO} 7$ in the first few minutes. However, in strong acidic conditions, the activation of PMS by $\mathrm{ZnO} @ \mathrm{Fe}_{3} \mathrm{O}_{4}$ was reduced so the degradation rate of $\mathrm{AO} 7$ became very slow since then. Besides, it could be seen that WMF had little effect on the electrostatic adsorption of $\mathrm{ZnO} @ \mathrm{Fe}_{3} \mathrm{O}_{4}$.

\subsection{Magnetic properties and reusability of $\mathrm{ZnO} @ \mathrm{Fe}_{3} \mathrm{O}_{4}$}

Since the influence of WMF is related to the magnetism of the catalyst, the magnetic properties of the film and the hysteresis

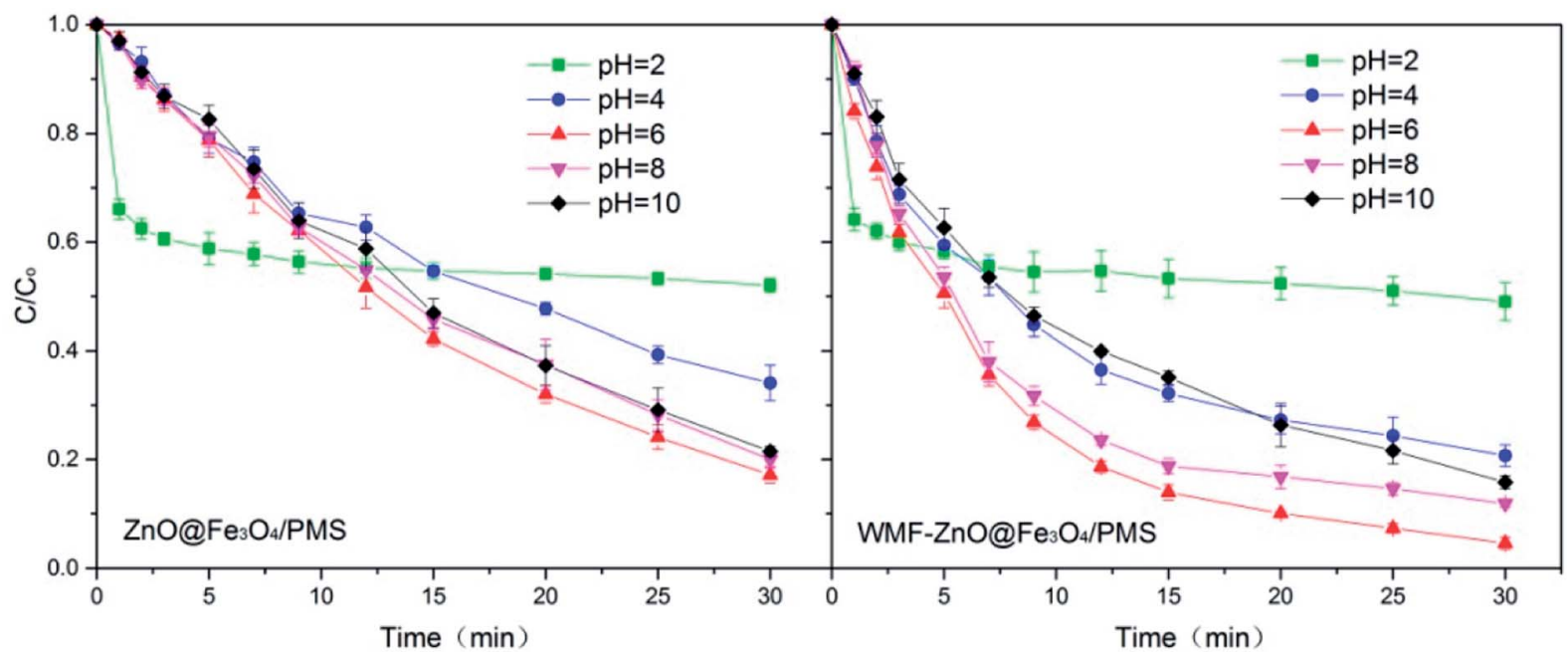

Fig. 6 Influence of WMF on $\mathrm{AO} 7$ removal by $\mathrm{ZnO}\left(\mathrm{FFe}_{3} \mathrm{O}_{4} / \mathrm{PMS}\right.$ system at different $\mathrm{pH}$ levels vary from 2.0 -10.0 . Reaction conditions: $[\mathrm{PMS}]_{0}=5$ $\times 10^{-4} \mathrm{M},[\mathrm{AO}]_{0}=0.02 \mathrm{mM},\left[\mathrm{ZnO} \mathrm{aFe}_{3} \mathrm{O}_{4}\right]_{0}=0.5 \mathrm{~g} \mathrm{~L}^{-1}$. 


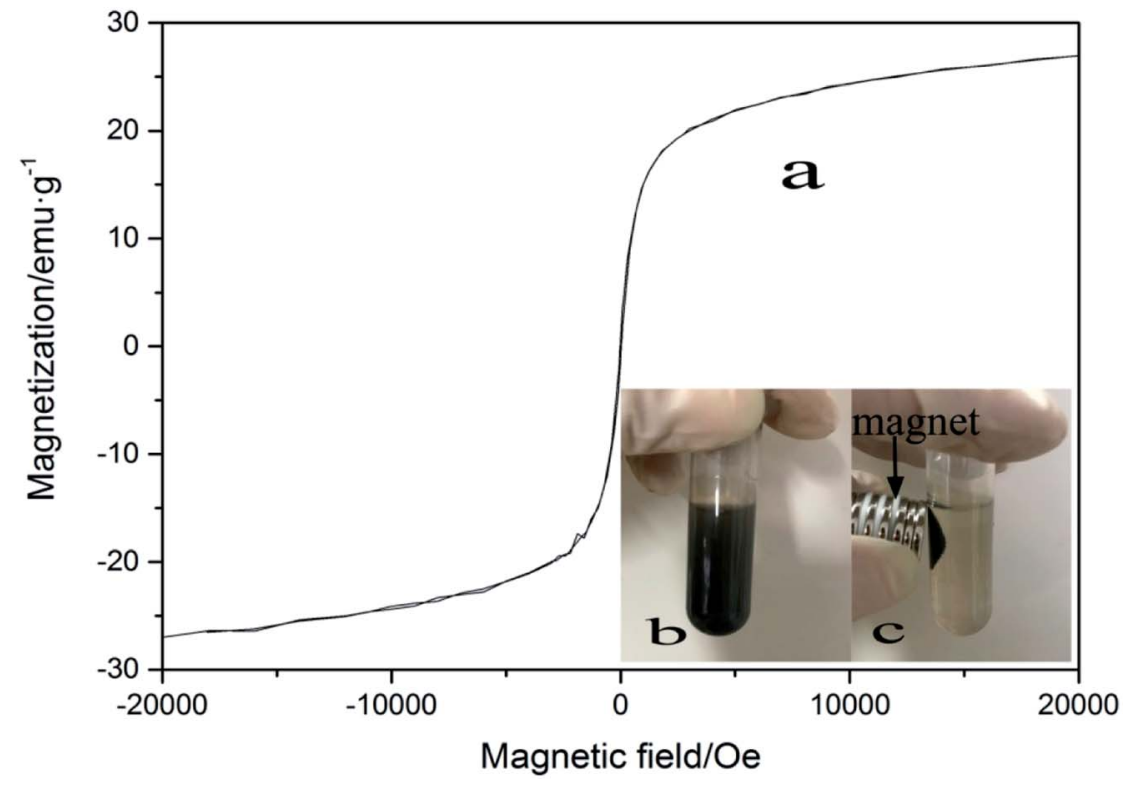

Fig. 7 (a) VSM curves of $\mathrm{ZnO} a \mathrm{Fe}_{3} \mathrm{O}_{4}$ (b) image of $\mathrm{ZnO}\left(\mathrm{Fe}_{3} \mathrm{O}_{4}\right.$ dispersed in pure water (c) image of $\mathrm{ZnO} \mathrm{aFe}_{3} \mathrm{O}_{4}$ external magnet.

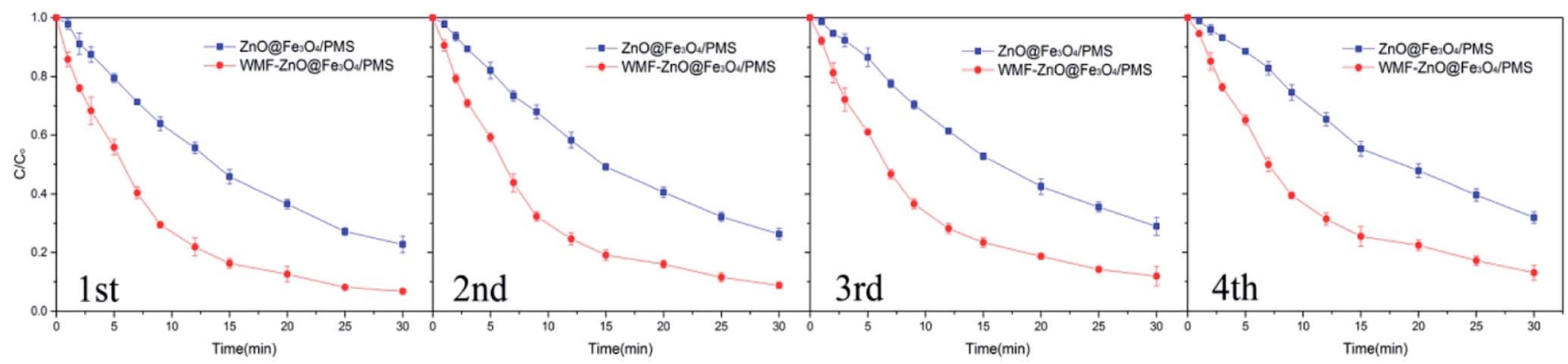

Fig. 8 Influence of WMF on $\mathrm{AO} 7$ removal in four consecutive cycles of $\mathrm{ZnO}\left(\mathrm{FFe}_{3} \mathrm{O}_{4}\right.$. Reaction conditions: $[\mathrm{PMS}]_{0}=5 \times 10^{-4} \mathrm{M},[\mathrm{AO} 7]_{0}=$ $10 \mathrm{mg} \mathrm{L}^{-1},\left[\mathrm{ZnO} \mathrm{aFe}_{3} \mathrm{O}_{4}\right]_{0}=0.5 \mathrm{~g} \mathrm{~L}^{-1}$.

loop of $\mathrm{ZnO@Fe}{ }_{3} \mathrm{O}_{4}$ was investigated, as shown in Fig. 7a. The magnetization was about $6 \mathrm{emu}^{-1}$ when the external magnetic field reached $20 \mathrm{mT}$. In this case, the removal rate of AO7 was the highest in our research. The magnetization might be the key to the effect of the catalyst.

As the reusability of the catalyst is an important parameter of

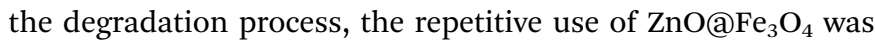

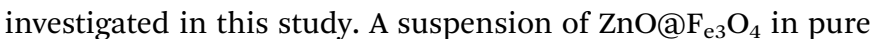
water is shown in Fig. 7b. When a magnet was applied to the suspension, the magnetic catalyst immediately accumulated to the side of the centrifuge tube near the magnet, leaving the solution colourless (Fig. 7c), and demonstrating a good magnetically separating property.

$\mathrm{AO} 7$ degradation with recycled $\mathrm{ZnO} @ \mathrm{Fe}_{3} \mathrm{O}_{4}$ was investigated under the same conditions used for the freshly-made catalyst (Fig. 8). After four cycles, about $87 \%$ of the added AO7 was removed with WMF. And it still increased AO7 degradation by $13 \%$ within $30 \mathrm{~min}$. The results showed the high reusability and stability of the catalyst and the effect of WMF on the recycled catalyst. And the reason for the slight decrease in degradation rate might be the reaction between $\mathrm{ZnO}$ and PMS, but it was a just small amount so the $\mathrm{ZnO} @ \mathrm{Fe}_{3} \mathrm{O}_{4}$ can maintain a high catalytic activity after repeated use.

\section{Conclusions}

The results of this study revealed the enhancing effect of WMF on $\mathrm{AO} 7$ removal by $\mathrm{ZnO} @ \mathrm{Fe}_{3} \mathrm{O}_{4} / \mathrm{PMS}$ system, which was of practical and fundamental importance to the environmental decontamination by the system. Furthermore, the corrosion of the catalyst did not increase with WMF which showed the catalytic reaction was induced predominately by the heterogeneous catalysis on the surface of $\mathrm{ZnO} @ \mathrm{Fe}_{3} \mathrm{O}_{4}$. Besides, the results revealed that both $\mathrm{SO}_{4}{ }^{-} / \mathrm{SO}_{5}{ }^{-}$and $\mathrm{O}_{2}{ }^{--}$radicals are involved in the catalytic reactions, but the $\mathrm{O}_{2}{ }^{--}$radicals are the mainly radicals affected by WMF. The production rate of $\mathrm{O}_{2}{ }^{-}$ radicals increased in the presence of WMF. In addition, the faster production and consumption of radicals promoted the reaction of $\mathrm{Fe}^{3+}$ and PMS which promoted the transition of $\mathrm{Fe}^{3+}$ to $\mathrm{Fe}^{2+}$ on the catalyst surface. The WMF effect observed in this 
study could be explained with the theory of radical-pair. Furthermore, the catalytic effect of the system was different beyond the appropriate magnetic field flux intensity and $\mathrm{pH}$.

\section{Conflicts of interest}

There are no conflicts to declare.

\section{Acknowledgements}

Appreciation and acknowledgment are given to the National Natural Science Foundation of China (No. 51508353).

\section{References}

1 R. L. Mcginnis and M. Elimelech, Environ. Sci. Technol., 2008, 42, 8625-8629.

2 T. E. Agustina, H. M. Ang and V. K. Vareek, J. Photochem. Photobiol., C, 2005, 6, 264-273.

3 C. He, Y. Xiong and X. Zhu, Thin Solid Films, 2002, 422, 235238.

4 N. L. Stock, J. Peller, K. Vinodgopal and P. V. Kamat, Environ. Sci. Technol., 2000, 34, 1747-1750.

5 X. Xiong, J. Gan, Z. Wei and S. Bo, Environ. Sci. Pollut. Res., 2016, 23, 16761-16770.

6 L. Liang, X. Guan, Y. Huang, J. Ma, X. Sun, J. Qiao and G. Zhou, Sep. Purif. Technol., 2015, 156, 1064-1072.

7 L. Liang, W. Sun, X. Guan, Y. Huang, W. Choi, H. Bao, L. Li and Z. Jiang, Water Res., 2014, 49, 371.

8 J. Li, H. Qin, W.-X. Zhang, Z. Shi, D. Zhao and X. Guan, Sep. Purif. Technol., 2017, 176, 40-47.

9 B. Brocklehurst, Chem. Soc. Rev., 2002, 33, 301-311.

10 C. He, X. Liu, W. Ji and J. Zhao, Water, Air, Soil Pollut., 2016, 227, 1-12.

11 J. Du, D. Che, X. Li, W. Guo and N. Ren, $R S C A d v .$, 2017, 7, 18231-18237.

12 W. Zhang, X.-X. Wang, H.-X. Lin and X.-Z. Fu, Acta Chim. Sin., 2005, 63, 1765-1768.

13 W. Zhang, X.-X. Wang, H.-X. Lin and X.-Z. Fu, Acta Chim. Sin., 2005, 63, 715-719.

14 F. Ji, C. Li, Y. Liu and P. Liu, Sep. Purif. Technol., 2014, 135, 16.

15 S. Muhammad, P. R. Shukla, M. O. Tadé and S. Wang, J. Hazard. Mater., 2012, 215-216, 183-190.
16 Y. Yao, Z. Yang, D. Zhang, W. Peng, H. Sun and S. Wang, Ind. Eng. Chem. Res., 2012, 51, 6044-6051.

17 K. R. Raghupathi, R. T. Koodali and A. C. Manna, Langmuir, 2011, 27, 4020-4028.

18 S. Singh, K. C. Barick and D. Bahadur, J. Hazard. Mater., 2011, 192, 1539-1547.

19 L. E. Bykova, V. G. Myagkov, I. A. Tambasov, O. A. Bayukov, V. S. Zhigalov, K. P. Polyakova, G. N. Bondarenko, I. V. Nemtsev, V. V. Polyakov and G. S. Patrin, Phys. Solid State, 2015, 57, 386-390.

20 E. B. Burlakova, Russ. Chem. Rev., 1975, 44, 871.

21 R. Palominos, J. Freer, M. A. Mondaca and H. D. Mansilla, J. Photochem. Photobiol., A, 2008, 193, 139-145.

22 I. Gültekin, G. Tezcanligüyer and N.-H. Ince, Ultrason. Sonochem., 2009, 16, 577-581.

23 N. Wang, L. Zhu, D. Wang, M. Wang, Z. Lin and H. Tang, Ultrason. Sonochem., 2010, 17, 526-533.

24 Z. R. Ismagilov, S. N. Pak and V. K. Yermolaev, J. Catal., 1992, 136, 197-201.

25 H. Yan, J. Zhang, C. You, Z. Song, B. Yu and Y. Shen, Mater. Chem. Phys., 2009, 113, 46-52.

26 A. Demir, A. Baykal, H. Sözeri and R. Topkaya, Synth. Met., 2014, 187, 75-80.

27 J. Wang, J. Yang, X. Li, D. Wang, B. Wei, H. Song, X. Li and S. Fu, Phys. E, 2016, 75, 66-71.

28 Y. Mizukoshi, T. Shuto, N. Masahashi and S. Tanabe, Ultrason. Sonochem., 2009, 16, 525-531.

29 H. Iida, K. Takayanagi, T. Nakanishi and T. Osaka, J. Colloid Interface Sci., 2007, 314, 274.

30 J. Xia, A. Wang, X. Liu and Z. Su, Appl. Surf. Sci., 2011, 257, 9724-9732.

31 P. Shukla, I. Fatimah, S. Wang, H. M. Ang and M. O. Tadé, Catal. Today, 2010, 157, 410-414.

32 J. Madhavan, P. Maruthamuthu, S. Murugesan and S. Anandan, Appl. Catal., B, 2008, 83, 8-14.

33 N. J. Turro and G. C. Weed, J. Am. Chem. Soc., 1983, 105, 1861-1868.

34 F. S. Barnes and B. Greenebaum, Bioelectromagnetics, 2015, 36, 45-54.

35 O. S. Furman, Environ. Sci. Technol., 2010, 44, 6423-6428.

36 C. K. Duesterberg, S. E. Mylon and T. D. Waite, Environ. Sci. Technol., 2008, 42, 8522-8527. 